\title{
Short Anagen Syndrome: A Case Study
}

\section{Martina Alés Fernández, Francisco M. Camacho Martínez}

Department of Dermatology, Virgen Macarena University Hospital, Seville, Spain. Email:malesfer@hotmail.com, camachodp@medynet.com

Received October $31^{\text {st }}, 2011$; revised November $18^{\text {th }}, 2011$; revised November $29^{\text {th }}, 2011$

\begin{abstract}
Short anagen syndrome is a relatively recently described entity. This syndrome is an unusual condition where the anagen growth phase of hair follicles is shorter than normal. Its clinical characteristics and trichogram findings contribute to the diagnosis of this trichosis.
\end{abstract}

Keywords: Anagen Syndrome

\section{Case Report}

Three-years-old girl with low density and slow growth scalp hair that had not been cut since birth. Her birth and medical history were unremarkable. The physical examination revealed short and fine brown scalp hair with decreased density in frontoparietal areas (Figure 1). The rest of the physical examination was normal, without any abnormalities in eyelashes, eyebrows, teeth, nails or skin. The hair pull test was negative. The trichogram demonstrated some dystrophic hairs, but the most important data was an increased number of telogen hairs with a consistent decreased number of anagen hairs (Figure 2). The anagen to telogen ratio $(7: 28)$ was significantly reduced with only $25 \%$ of hairs in anagen.

\section{Discussion}

Short anagen syndrome is a relatively recently recognized entity poorly documented. Short hair due to a short anagen phase was described in 1987 by Kersey as part of tricho-dental syndrome [1]. In 1993 Headington review telogen effluvium in association with idiopathic shortening of anagen [2]. In 1999 De Berker reported short anagen syndrome like a congenital hypotrichosis [3] and Withmore \& Tausk described this syndrome in a 19years-old woman [4].

The normal ratio of anagen to telogen is 9:1 and the ratio of the duration of these phases of the hair cycle in normal hair growth is parallel. In children between 3 and 11 years old $90 \%$ of the hair are in the anagen phase. Nevertheless in short anagen syndrome the ratio of anagen to telogen could reach 4:50 [5].

The incidence is unknown, although it is clear that this condition appears from birth and more frequent in blond hair with a female predominance, with spontaneous reso-

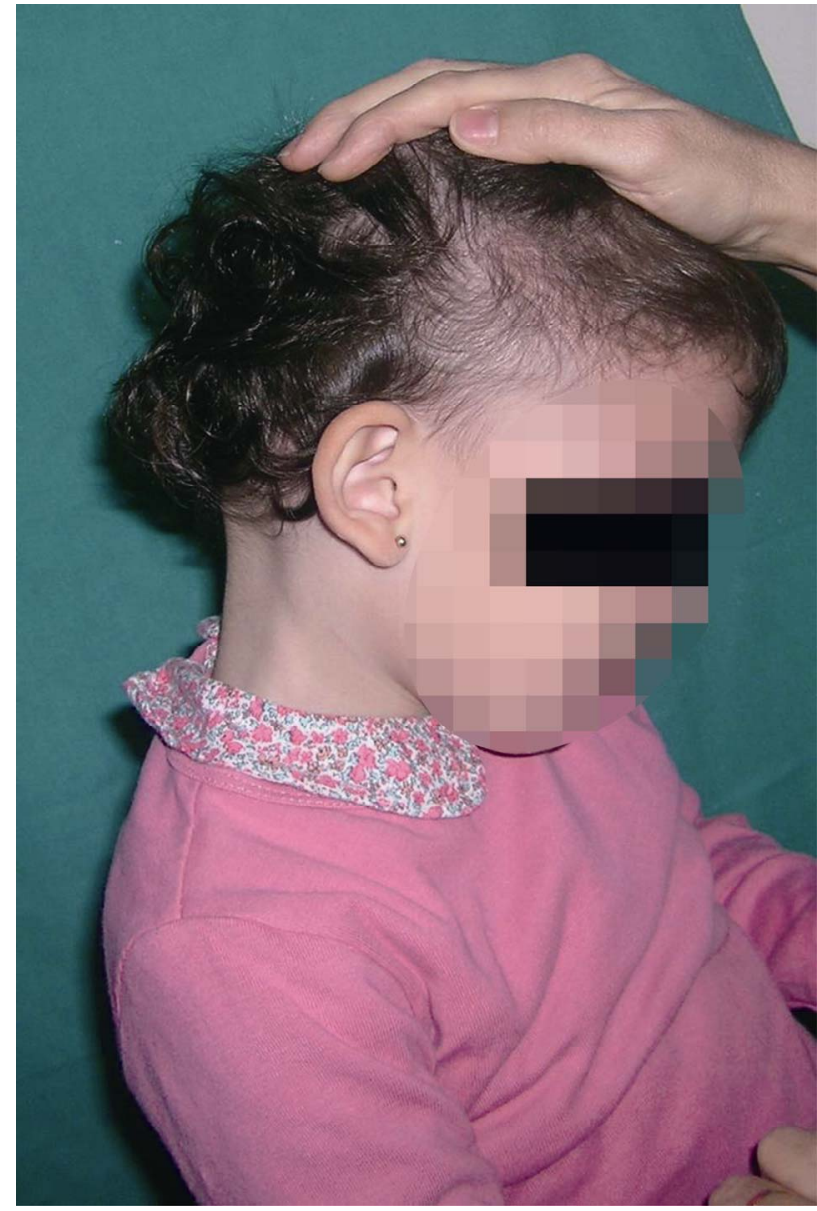

Figure 1. Typical decreased density in frontoparietal areas.

lution during the puberty and adulthood. There are few cases reported with a probable autosomal dominant inheritance [6]. The patients have a history of congenital 


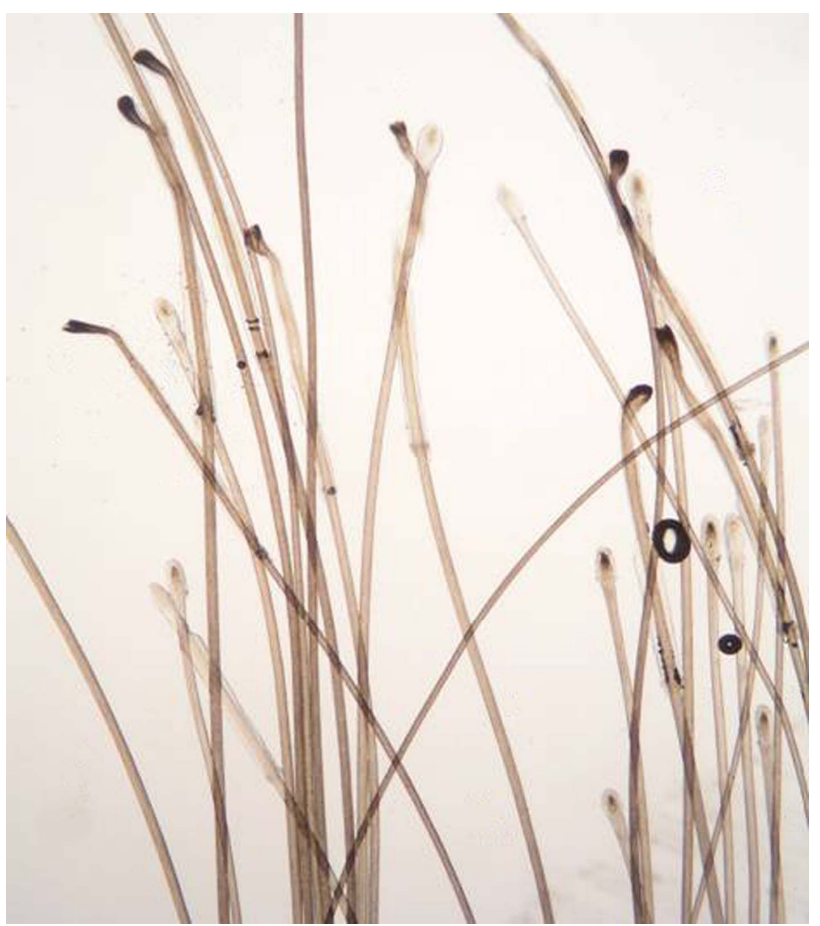

Figure 2. Increased number of telogen hairs with a consistent decreased number of anagen hairs.

short hair and low density hair that had not been cut since birth, without fragility or hair loss tendency [7]. Typical the hair is less dense in front-parietal hairline and does not grow beyond the ears. The hair pull test is negative.

The clinical diagnosis is based on the clinic history and the physical examination, because hair is thinned in appearance and typically does not grow beyond the neck. The tricogram demonstrate the decrease of anagen hairs proportion between telogen hairs [8]. The main differential diagnosis is with loose anagen syndrome, wich is a hairy dysplasia characterized by anagen hairs easily and painlessly pulled. In this condition trichogram shows disturbed "naked" shaft immediately distal to the bulb, absent sheaths and segments with ruffled cuticle. Treat- ment is not necessary since spontaneous normalization can be expected with the onset of puberty.

In conclusion, short anagen syndrome is a relatively recently described entity scantly documented with a low frequency of presentation in the daily clinic. The knowledge of the clinical and trichological characteristics makes the diagnosis possible.

\section{REFERENCES}

[1] P. J. W. Kersey, "Tricho-Dental Syndrome: A Disorder with Short Hair Cycle," British Journal of Dermatology, Vol. 116, No. 2, 1987, pp. 259-263. doi:10.1111/j.1365-2133.1987.tb05824.x

[2] J. T. Headington, "Telogen Effluvium," Archives of Dermatology, Vol. 129, 1993, pp. 356-363. doi:10.1001/archderm.129.3.356

[3] D. De Berker, "Congenital Hyptrichosis," International Journal of Dermatology, Vol. 38, 1999, pp. 25-33.

[4] S. E. Whitmore and F. A. Tausk, "Short Anagen Syndrome," American Journal of Clinical Dermatology, Vol. 2, 1999, pp. 30-32.

[5] R. J. Antaya, E. Sideridou and E. A. Olsen, "Short Anagen Syndrome," Journal of the American Academy of Dermatology, Vol. 53, No. 2, 2005, pp. 130-134. doi:10.1016/i.jaad.2004.12.029

[6] M. M. Barraud-Klenovsek and R. M. Trüeb, "Congenital Hypotricosis Due to Short Anagen," British Journal of Dermatology, Vol. 143, No. 3, 2000, pp. 612-617. doi:10.1111/j.1365-2133.2000.03720.x

[7] F. Giacomini, M. Starace and A. Tosti, "Short Anagen Syndrome," Pediatric Dermatology, Vol. 28, No. 2, 2011, pp. 133-134. doi:10.1111/j.1525-1470.2010.01165.x

[8] K. Thai, B. Med and D. Rodney, "Short Anagen Hair with Persistent Syncronized Pattern of Scalp Hair Growth," Journal of the American Academy of Dermatology, Vol. 49, No. 5, 2003, pp. 949-951. doi:10.1016/S0190-9622(03)00453-5 